\title{
Histamine Releasing Factor/Translationally Controlled Tumor Protein: History, Functions and Clinical Implications
}

\author{
Susan M. MacDonald*
}

The Johns Hopkins Asthma and Allergy Center, 5501 Hopkins Bayview Circle Room 3B.69, Baltimore, MD 21224, USA

\begin{abstract}
Histamine Releasing Factor (HRF) also known as Translationally Controlled Tumor Protein (TCTP) is a ubiquitous, novel protein that has both intracellular and extracellular functions. The purpose of this review is to highlight the background history of the molecule, the clinical implications and focus on the extracellular functions. Specifically the cells and the cytokines that are produced when stimulated by HRF/TCTP will be delineated as well as the signal transduction pathway that HRF/TCTP elicits will be described. Originally it was thought that HRF/TCTP interacted with IgE. Subsequently, cells that do not bind IgE also respond to HRF/TCTP and the interaction with IgE was questioned. Now, very recently, HRF/TCTP or at least its mouse counterpart appears to interact with some, but not all $\operatorname{IgE}$ and $\operatorname{IgG}$ molecules. HRF/TCTP has been shown to activate multiple human cells including basophils, eosinophils, T cells and B cells. Many of the cells that are activated by HRF/TCTP participate in the allergic response, leading to the conclusion that the extracellular functions of HRF/TCTP could exacerbate the allergic, inflammatory response.
\end{abstract}

Keywords: Histamine Releasing Factor (HRF), Human Basophils, Human Eosinophils, Inducible Transgenic Mouse, Interleukin 4, Interleukin 13, Mast Cells, Translationally Controlled Tumor Protein (TCTP).

\section{INTRODUCTION}

Histamine Releasing Factor (HRF) was originally identified in the 1980s by Brawerman's group as a tumor protein (Translationally Controlled Tumor Protein, TCTP) in a mouse acidic tumor and in mouse erythroleukemia. However, no function for the protein was identified $[1,2]$. We identified a histamine releasing activity that was found in late phase fluids from nasal lavages, bronchoalveolar lavage fluids (BAL) and skin blister fluids that directly induced histamine release from basophils isolated from a subpopulation of allergic donors (HRF-Responders [HRF/TCTP-R]) [3]. After purification and cloning, HRF was found to be identical to TCTP, which is also known as p23 [4]. This recombinant molecule was found to have the same properties as the originally described HRF/TCTP derived from nasal secretions, namely, an ability to induce histamine release from selected donors. This protein is ubiquitously expressed as an intracellular protein, and homologs of HRF/TCTP have been described in parasites including Plasmodium falciparum, Wucheria bancrofti, Brugiia malea and Schistosoma Mansinai, all of which possess mast cell/basophil histamine releasing activity [5-7]. Our group, as well as another group, has identified the interaction between HRF and elongation factor-1 $\delta$, also known as eElongation factor $1 \mathrm{~B}-\beta[8,9]$. Thus, HRF/TCTP may have an intracellular role in interfering with the elongation step of protein synthesis.

*Address correspondence to this author at the The Johns Hopkins Asthma and Allergy Center, 5501 Hopkins Bayview Circle Room 3B.69, Baltimore, MD 21224, USA; Tel: 410-550-2075; Fax: 410-550-2090;

E-mail: smacdona@jhmi.edu

\section{HRF/TCTP CELLULAR INTERACTIONS}

HRF/TCTP has no leader sequence. It was not until Amzallage et al documented that it is was secreted by an ER/Golgi-independent route that its secretion was understood [10]. Furthermore, they documented that secreted HRF/TCTP comes from an existing intracellular pool and co-distributes with TSAP6, a member of a family that is involved in vesicular trafficking and secretory processes [1012]. We, as well as others, have focused on the extracellular functions of HRF/TCTP. HRF was initially described as a complete secretagogue for histamine and IL-4 secretion from basophils of allergic donors [13]. Initially, these donors were thought to have a certain type of $\operatorname{IgE}$ that interacted with HRF/TCTP to induce secretion [4]. However, it was subsequently demonstrated that HRF/TCTP primed all basophils for histamine release, IL-4 and IL-13 secretion regardless of the type of IgE [14]. Additional studies demonstrated that HRF/TCTP did not appear to interact with IgE. Namely, pharmacologic agents that altered HRF/TCTP-induced histamine release, i.e. rotterlin, did not affect anti-IgE-induced histamine release [15]. Also, rat basophilic leukemia cells transfected with the $\alpha, \beta$ and $\gamma$ chains of the human IgE receptor, FceRI, did not release histamine to HRF/TCTP despite sensitization with IgE molecules from an HRF/TCTPR- donor [16]. Furthermore, HRF/TCTP was shown to stimulate eosinophils to produce IL-8 and induce an intracellular calcium response [17]. This was also observed in the eosinophil cell line, AML-3D10, which does not express the $\alpha$ chain of the FceR1 on the surface of the cell [17]. Very recently, HRF/TCTP was found to have an inflammatory role in mouse models of asthma and allergy [18]. In this manuscript HRF/TCTP was found to exist as a dimmer and bound to a subset of $\operatorname{IgE}$ and $\operatorname{IgG}$ antibodies by interacting 
by its $\mathrm{N}$-terminus and the internal regions with the Fab region of immunoglobulins. All of these interactions were described with mouse HRF/TCTP and interacted on mouse mast cells.

Additionally, HRF/TCTP has been shown to inhibit cytokine production from stimulated primary $\mathrm{T}$ cells and the Jurkat $\mathrm{T}$ cell line at the level of gene transcription [19]. Thus, HRF/TCTP, in addition to functioning as a histamine releasing factor, can modulate secretion of cytokines from human basophils, eosinophils and $\mathrm{T}$ cells. Furthermore, Kang et al have identified this molecule as a B cell growth factor. They demonstrated that HRF/TCTP bound to B cells and induced cytokine production [20]. More recently, HRF/TCTP was shown to stimulate bronchial epithelial cells to produce IL-8 and GM-CSF [21].

\section{INTRACELLULAR FUNCTIONS OF HRF/TCTP}

Although this review mainly focuses on the extracellular functions of HRF/TCTP, it is important to mention some of the broad spectrum of intracellular functions. HRF/TCTP is both transcriptionally and post-transcriptionally regulated by calcium [22]. It is also a tubulin binding protein and has been shown to transiently associate with microtubules during the cell cycle [23]. Also the vitamin D receptor, NEMO, the myeloid cell leukemia protein 1 (MCL1) and Bcl-XL have been demonstrated to interact with HRF/TCTP [24-27]. Additionally high levels of HRF/TCTP have been associated with various cancers, such as prostate, breast and colon cancer [28-30]. Furthermore, the gene for HRF/TCTP was down regulated in tumor reversion and more specifically, the level was significantly reduced in a lung cancer cell line, A549, revertant cells [31]. The role of HRF/TCTP in tumor development may be associated with its anti-apototic activity [27, 32]. This is further supported by reports of HRF/TCTP antagonizing bax function and controlling the stability of the tumor suppressor p53 $[33,34]$. In a very recent publication HRF/TCTP promoted p53 degredation and p53 directly repressed HRF/TCTP transcription [35]. Thus HRF/TCTP may be extremely relevant in cancer due to this report of a previously unrecognized regulatory circuit [35]. Moreover as previously mentioned, our lab and others have shown involvement of HRF/TCTP in the elongation step of protein synthesis $[8,9]$. Thus intracellularly, HRF/TCTP has a wide range of functions. The extracellular function seems however, to focus on inflammation.

\section{CLINICAL RELEVANCE OF HRF/TCTP}

The importance of the association of HRF/TCTP with human asthmatic, allergic disease has been previously documented in numerous publications. For instance, HRF/TCTP has been found in human respiratory secretions (BAL) and skin blister fluids [3]. Since only certain donor's basophils release histamine when exposed to HRF/TCTP, we undertook a study to define the responding population. Sixty-four ragweed allergic patients with a history of seasonal rhinitis and one or more positive skin tests were compared to 17 nonatopic controls who were skin test negative. Sensitivity to HRF/TCTP was restricted to the subpopulation of atopic individuals [36]. In a separate study of 55 ragweed allergic patients, there was a significant correlation between the intensity of symptoms in the late phase reaction and ba- sophil histamine release to HRF/TCTP [37]. In studies from another group, peripheral blood mononuclear cells from patients with asthma spontaneously produced HRF/TCTP [38, 39]. The production of that HRF/TCTP correlated with bronchial hyperreactivity and the bronchial sensitivity to methacholine of the patient was correlated with the magnitude of HRF/TCTP production [40]. Sampson et al have shown that production of HRF/TCTP also is associated with clinical status of food allergy and atopic dermatitis [41]. Using blood from food allergic children with atopic dermatitis, they found that their basophils have a high spontaneous release of histamine and their cultured mononuclear cells spontaneously produce HRF/TCTP. When these children were placed on an avoidance diet, they improved clinically, their basophils no longer spontaneously secreted histamine, and their mononuclear cells no longer spontaneously produced HRF/TCTP. Two groups have reported the effects of immunotherapy on HRF/TCTP production. One group showed a striking correlation between the production of HRF/TCTP by mononuclear cells and the change in bronchial sensitivity to histamine (PC20), after two years of immunotherapy [42]. Brunet et al showed immunotherapy in allergic rhinitis patients without asthma, improved symptoms and also avoided the seasonal increase of spontaneous and antigen driven HRF/TCTP production from peripheral blood mononuclear cells [43]. Moreover, we have measured HRF in human BAL fluids of allergics following antigen challenge. While HRF/TCTP increases over baseline after antigen challenge, it is not significant with the number of patients $(n=8)$ we have investigated (unpublished observations).

With the availability of recombinant material, we examined the lymphocytes of allergic and non-allergic patients for the generation of HRF/TCTP mRNA and protein. Twelve patients (four HRF/TCTP-R, four HRF/TCTP-Non Responder (NR) and four non-allergic) were recruited. Blood was drawn for serum IgE measurements and for basophil histamine release in response to recombinant HRF/TCTP and anti-IgE. In addition, peripheral blood mononuclear cells were cultured for HRF/TCTP production and processed for mRNA extraction and subsequent reversed transcribed polymerase chain reaction for HRF/TCTP mRNA. The geometric mean serum IgE levels were $356 \mathrm{ng} \mathrm{ml}^{-1}$ in the HRF/TCTP-R group versus $52 \mu \mathrm{g} \mathrm{ml}^{-1}$ and $4.2 \mu \mathrm{g} \mathrm{ml}^{-1}$ in the HRF/TCTP-NR and non-allergic subjects, respectively. Histamine release in response to the recombinant HRF/TCTP paralleled that of our native HRF/TCTP preparation in that only the four HRF/TCTP-R patients release histamine to this stimulus. The quantity of mRNA for HRF/TCTP, when compared to that for beta actin, the housekeeping gene, did not appear different among the groups. The bioactivity of the recombinant HRF/TCTP on lactic acid treated cells passively sensitized with an IgE containing serum from a HRF/TCTP$\mathrm{R}$, however, was greater in the allergic, HRF/TCTP-R patients than in the non-allergic subjects $[44,45]$. Thus, it appears that all individual make mRNA for HRF/TCTP but atopic subjects more effectively translate it to protein.

Based on the above observations, we believe that HRF/TCTP may be an important element of the pathogenesis of asthmatic allergic diseases. Since HRF/TCTP is present in late phase reaction fluids in vivo, it may be contributing to mediator release that is found in the late response. Further 
understanding of the biology of HRF/TCTP may help explain the varying severities of asthmatic, allergic disease.

\section{HRF/TCTP PRIMING RESPONSE}

It has long been appreciated that human basophils are cells that are capable of being "primed" or having an enhanced functional response. Some of the molecules that are known to prime human basophils include IL-3, NGF, HRF/TCTP and the non-physiologic stimulus $\mathrm{D}_{2} \mathrm{O}[46,47]$. In general, these substances show a greater releasability (as evidenced by histamine or IL-4 secretion) when stimulating basophils from allergic or allergic, asthmatic subjects. Normally, they do not generally activate basophils from normal subjects. The exception to this is the HRF/TCTP-R basophils. Basophils from these subjects are directly activated by IL-3 and HRF/TCTP [4, 48].

\section{GENERATION OF AN INDUCIBLE HRF/TCTP TRANSGENIC MOUSE}

Although HRF/TCTP has been extensively investigated for many years, most studies have been carried out in cultured cells and pathologic samples. Until recently, there has been no established animal model available to explore the function of HRF/TCTP. One group generated HRF/TCTP knockout mice by targeted gene disruption [49]. However, these HRF/TCTP knockout mice were embryonically lethal. Since HRF/TCTP is ubiquitous and highly conserved, our approach has been to create an inducible HRF/TCTP mouse model using the Tet On system. We wanted to target HRF/TCTP to the lungs, so we used the CC10 promoter that is expressed in Clara cells of the lung epithelium. We generated a transgenic TRE-HRF-EGFP mouse. Using this model, we see an enhanced asthmatic, allergic phenotype after OVA challenge [50]. This enhancement is seen in the C57BL/6 mouse, not the traditional "allergic" BALB/c mouse. The development of an inducible-transgenic HRF/TCTP animal model will yield insights into its underlying pathophysiologic characteristics and provide a tool to define the mechanism of this enhanced or primed phenotype.

The mechanism of HRF/TCTP's enhanced response yielding increases in IL-4, IgE and eosinophils after OVA challenge in our transgenic model is currently unknown. It is interesting to speculate that all of these events could be attributed to the action of HRF/TCTP on the basophil. This hypothesis is plausible considering the data on HRF/TCTP and the human basophil. We have shown that HRF/TCTP activates human basophils to produce IL-4 [13]. It is well accepted that IL-4 is important for B cell class switching and production of $\operatorname{IgE}$. Furthermore, human basophils possess the $\beta-1$ integrin that is important for firm adhesion of the basophil. The ligand for $\beta-1$ integrin is vascular cell adhesion molecule (VCAM-1) that is upregulated by IL-4 and is important for the transendothelial migration of eosinophils and Th2 cells [46]. Therefore, basophils by producing IL-4 could explain the enhanced asthmatic, allergic phenotype we see after over production of HRF/TCTP in our OVA challenged model. However, this could only be possible if the mouse basophil acted in a similar manner as its human counter part. The existence of the mouse basophil dates back over two decades [51]. However, in the last several years, this cell has re-emerged as an important initiator in mouse Th2 inflammation [52, 53].

It is well accepted that asthma is a multifactorial disease. Therefore, it is highly unlikely that one single cell such as the mouse basophil is totally responsible for HRF/TCTP's effect on asthmatic lung disease. Since we know HRF/TCTP activates eosinophils [17] and since we find increased eosinophils in the BAL fluid of the OVA challenged transgenic mouse [50], it is logical to assess the role of this cell in the mechanisms of action of HRF/TCTP in vivo. It is well known that the activation, recruitment and proliferation of the $\mathrm{T}$ cell is associated with asthmatic lung disease [54]. Additionally, in the congenitally eosinophil-deficient PHIL mouse, there is a diminution of Th2 responses [55]. Furthermore, eosinophils also secrete IL-4 [56] and act as antigen-presenting cells yielding $\mathrm{T}$ cell activation after allergen provocation in the lung [54]. Therefore, HRF/TCTP may exert additional enhancing effects through the eosinophil. An antibody to IL-5 has been shown to suppress eosinophil recruitment following OVA challenge in WT and FceR $\alpha-/-$ mice [56]. Giving anti-IL-5 to our OVA challenged HRF/TCTP mice would determine HRF/TCTP's mechanism upon eosinophil recruitment. Alternatively crossbreeding our HRF/TCTP transgenic mice with the eosinophil knockout PHIL mouse could ablate all HRF/TCTP-induced enhancing effects or just affect eosinophils. As with all in vivo experimentation, one must be mindful of additional effects that could contribute to phenotype and mechanism in question. In the case of anti-IL-5 treatment, immunoglobulin controls could be monitored. In the case of crossbreeding with the PHIL mouse, WT controls could be monitored.

\section{INTRACELLULAR SIGNALING BY HRF/TCTP}

Another possible mechanism of action for HRF/TCTP may be IgE-dependent enhancement. Originally, HRF/TCTP was called the IgE-dependent HRF [4]. This designation resulted from the fact that HRF seemed to act as a secretagogue for human basophils from a subpopulation of allergic donors. Moreover, passive sensitization of serum containing IgE from these responding donors rendered nonresponsive donors' basophils responsive to HRF/TCTP [4]. Subsequent to that observation, HRF/TCTP was shown to activate other cells that do not possess the high affinity $\operatorname{IgE}$ receptor, FceR1 [17, 19]. Additionally, we have published that HRF/TCTP has signal transduction events that are similar, but not identical, to signaling through FceR1 [57]. With the availability of both the FceR $1 \alpha$ knockout mouse and the IgE knockout mouse [58, 59], the question of whether HRF/TCTP is dependent on IgE can be definitively addressed. As previously mentioned, a manuscript has very recently been accepted that demonstrates mouse HRF/TCTP does bind to certain IgE and IgG molecules [18].

In order to address the molecular mechanisms of HRF/TCTP-induced priming and secretion, we designed experiments to elucidate specific actions of HRF/TCTP on human basophils and to characterize the nature of intracellular signaling that follows stimulation with HRF/TCTP. Given the similarities in secretion kinetics following IgEmediated stimulation, we hypothesized there would be some signaling characteristics similar to those previously found for IgE-mediated release. However, due to the differential sensi- 


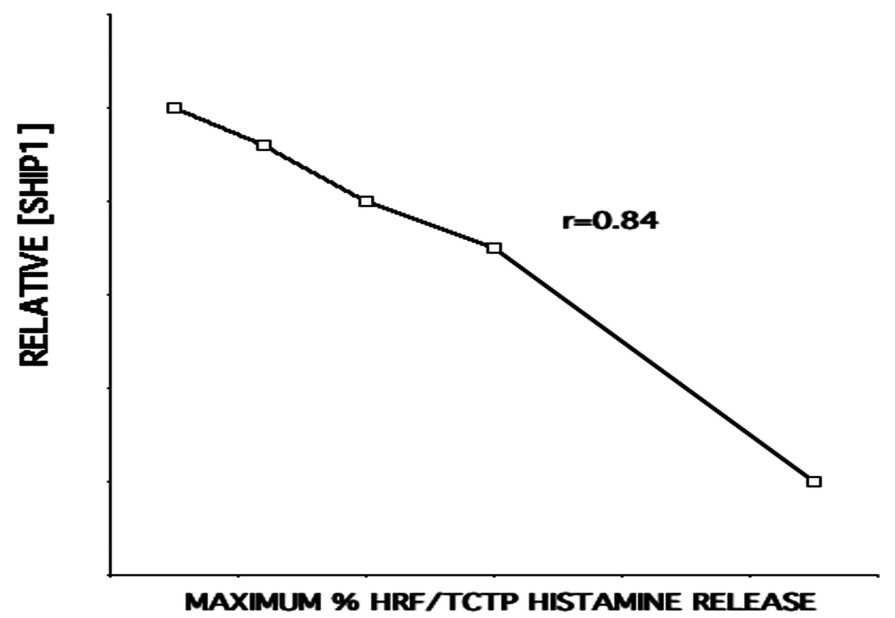

Fig. (1). SHIP1 is inversely correlated with the maximum histamine release to HRF/TCTP. Adapted from reference [65].

tivity to treatment with rotterlin between HRF/TCTP and anti-IgE [15], we also expected differences in signaling. We used human basophils from two donor populations, HRF/TCTP-R and HRF/TCTP-NR. Consistent with the ability of HRF/TCTP to either induce secretion directly from HRF/TCTP-R basophils or prime HRF/TCTP-NR basophils, we have shown binding of HRF/TCTP by flow cytometry to both donor populations [57]. We have demonstrated HRF/TCTP induced activation of intracellular signal transduction events in basophils only from those donors who directly release histamine to HRF/TCTP, namely, HRF/TCTPR. Specifically, we have been able to demonstrate increases in the arachodonic acid metabolite, $\mathrm{LTC}_{4}$, from basophils of HRF/TCTP-R donors stimulated with anti-IgE. Additionally, we have demonstrated $\mathrm{LTC}_{4}$ release from basophils stimulated with HRF/TCTP [57]. One might predict that this might well be due to prolonged phosphorylation of MEK and ERK 1/2. Miura et al have demonstrated in human basophils isolated from leukopheresis packs that activation of ERK1/2 is linked to arachodonic acid metabolism but not to histamine or IL-4 release [60]. Phosphorylation of ERK1/2 is transient, peaks at 5 minutes and returns to baseline by 30 minutes. We have demonstrated that both MEK and ERK1/2 are phosphorylated by HRF/TCTP in basophils from HRF/TCTP-R donors but not from HRF/TCTP-NR donors [57]. Thus, the characteristics of the signaling responses were very similar to those observed for stimulation with antiIgE antibody or antigen with a couple of exceptions. Notably, there was no phosphorylation of FceR $1 \gamma$, and there was absolutely no phosphorylation of any downstream signal transduction molecules in the HRF/TCTP-NR basophils.

\section{HRF/TCTP RELEASABILITY AND EFFECTS ON SHIP1}

The molecular basis for the releasability of the HRF/TCTP's basophils remained elusive until relatively recently. As previously mentioned, HRF/TCTP-R donors, who respond directly to HRF/TCTP, also release histamine to IL-3 and $\mathrm{D}_{2} \mathrm{O}[47,48]$. It has become accepted that the term, releasability (i.e. control of release of mediators from basophils in response to different stimuli) involves several biochemical events in addition to the surface density of $\operatorname{IgE}$ molecules. There have been reports of certain signaling molecule deficiencies in nonreleasing basophils [61, 62].
While these deficiencies are documented, there is little variation of SHIP-1 in the general population [63]. To date, we are the first group to show the negative association of the phosphatase, SHIP-1, with histamine release to HRF/TCTP in hyperreleasing basophils [64] (See Fig. 1). Variation of SHIP-1 levels is also documented in a subset of patients with chronic idiopathic urticaria. Levels of SHIP-1 are increased and anti-IgE-induced histamine release is reduced [65]. Thus, SHIP-1 levels appear to be altered in some human disease states.

A clue to the underlying mechanisms of increased releasability of basophils was demonstrated in a mouse knockout of SHIP-1 [66, 67]. Mast cells grown from the bone marrow (BMMC) of SHIP-1 knockout mice showed decreased hydrolysis of phosphatidyl-inositol (PI)-3,4,5, $\mathrm{P}_{3}\left(\mathrm{PIP}_{3}\right)$ [67]. SHIP-1 participates in the pathway in which the lipid phosphatidyl-inositol 4,5 bisphosphate $\left(\mathrm{PI} 4,5, \mathrm{P}_{2}\right)$ is phosphorylated by $\mathrm{PI} 3$ kinase to produce $\mathrm{PIP}_{3}$ which can be acted upon to produce $\mathrm{PI}(3,4)$ bisphosphate $\left(\mathrm{PI} 3,4 \mathrm{P}_{2}\right)[68,69]$. We have demonstrated that the compound, LY294002, which is an inhibitor of PI3 kinase, inhibits histamine release induced by HRF/TCTP in basophils from HRF/TCTP-R donors [64]. The activity of PI3 kinase is central to many basophil functions, and SHIP-1 acts to oppose the function of PI3 kinase by removing the 5'phosphatase from PIP $_{3}$. SHIP-1 becomes an important regulator of these reactions. The mouse SHIP-1 knockout mast cells had an excess of $\mathrm{PIP}_{3}$ that resulted in a sustained calcium signal that was critical for degranulation [70]. Additionally, $\mathrm{PIP}_{3}$ recruits the serine tyrosine kinase, Akt, to the plasma membrane [71]. Akt is present in human basophils and is transiently phosphorylated after anti-IgE stimulation [72]. Moreover, Akt is phosphorylated by HRF/TCTP in HRF/TCTP-R donors but not in HRF/TCTPNR donors [57]. Furthermore, we see prolonged Akt phosphorylation kinetics in HRF/TCTP-R [57]. This further supports the involvement of this pathway in HRF induced activation. Data from the SHIP-1 knockout mice and our own published data suggest that SHIP-1 may play a "gatekeeper role" in mouse and human basophils and mast cells. One would expect SHIP-1 to limit effector cell responsiveness in normal individuals, while a SHIP-1 deficiency would predispose an individual to excess inflammatory-mediator production and, hence, a hyperreleasable phenotype. 
In order to address this more directly, we altered SHIP-1 levels in human basophils. However, these studies have been limited by the fact that the basophil is an end stage nondividing cell and extremely difficult to transfect or transduce. Many attempts have been tried to transfect primary human basophils. These include lipid based reagents, lentivirus and nucleofection. Most failed either due to toxicity or very low transfection efficiency. Only nucleofection (Amaxa) gave a limited transfection efficiency that is useful only for single cell analysis [73]. There is one report that a TAT-fusion protein was used in transfecting human basophils [74]. We set out to determine a more efficient method of altering signal transduction pathways in human basophils. To that end, we established a model of culturing human peripheral blood derived basophils from CD34+ cells that have the morphologic and functional characteristics of human basophils [75]. We utilized this model to alter SHIP-1 levels using siRNA technology and demonstrated a decrease in SHIP-1 levels that was associated with an increase in histamine release to HRF/TCTP. Using CD34+ peripheral derived basophils, it is possible to perform a more direct test of the hypothesis that SHIP-1 has a role in modulating basophil responsiveness, both to HRF/TCTP and IgE-mediated stimulation.

\section{CONCLUSION}

In summary, further defining the extracellular role of the mechanism of HRF/TCTP-induced priming in vivo using our HRF/TCTP inducible transgenic mouse and in vitro using both peripheral blood derived basophils and CD34+ peripheral derived cultured basophils could yield additional insight into HRF/TCTP's participation in the propagation of the Th2 asthmatic allergic response. The successful completion of these studies could lead to an inhibition of the function of this unique cytokine and its amelioration of its role in the allergic, asthmatic diathesis.

\section{DISCLOSURE}

Aquinox Pharmaceutical, Inc. Member of the Scientific Advisory Board.

\section{ACKNOWLEDGEMENT}

None declared.

\section{REFERENCES}

[1] Yenofsky R, Cereghini S, Krowczynska A, Brawerman G. Regulation of mRNA utilization in mouse erythroleukemia cells induced to differentiate by exposure to dimethyl sulfoxide. Mol Cell Biol 1983; 3:1197-203.

[2] Chitpatima ST, Makrides S, Bandyopadhyay R, Brawerman G. Nucleotide sequence of a major messenger RNA for a 21 kilodalton polypeptide that is under translational control in mouse tumor cells. Nucleic Acids Res 1988;16:2350.

[3] MacDonald SM, Lichtenstein LM, Proud D, Plaut M, Naclerio RM, Kagey-Sobotka A. Studies of IgE-dependent histamine releasing factors: Heterogeneity of IgE. J Immunol 1987; 139:506-12.

[4] MacDonald SM, Rafnar T, Langdon J, Lichtenstein LM. Molecular identification of an IgE-dependent histamine releasing factor. Science $1995 ; 269: 688-90$.

[5] MacDonald SM, Bhisutthibhan J, Shapiro TA, et al. Immune mimicry in malaria: Plasmodium falciparum secretes a functional histamine-releasing factor homolog in vitro and in vivo. Proc Natl Acad Sci USA 2001; 98:10829-32.
Rao KV, Chen L, Gnanasekar M, Ramaswamy K. Cloning and characterization of a calcium-binding histamine-releasing protein from Schistosoma mansoni. J Biol Chem 2002; 277:31207-13.

[7] Gnanasekar M, Rao KV, Chen L, et al. Molecular characterization of a calcium binding translationally controlled tumor protein homologue from the filarial parasites Brugia malayi and Wuchereria bancrofti. Mol Biochem Parasitol 2002; 121:107-18.

[8] Langdon JM, Vonakis BM, MacDonald SM. Identification of the interaction between the human recombinant histamine releasing factor/translationally controlled tumor protein and elongation factor-1 delta (also known as eElongation Factor-1B beta). Biochem Biophys Acta 2004; 1688:232-6.

[9] Cans C, Passer BJ, Shalak V, et al. Translationally controlled tumor protein acts as a guanine nucleotide dissociation inhibitor on the translation elongation factor eEF1A. Proc Natl Acad Sci USA 2003; 100:13892-7.

[10] Amzallag N, Passer BJ, Allanic D, et al. TSAP6 facilitates the secretion of translationally controlled tumor protein/histaminereleasing factor via a nonclassical pathway. J Biol Chem 2004; 279:46104-12.

[11] Moldes M, Lasnier F, Gauthereau X, et al. Tumor necrosis factoralpha-induced adipose-related protein (TIARP), a cell-surface that is highly induced by tumor necrosis factor-alpha and adipose conversion. J Biol Chem 2001; 276:33938-46.

[12] Korkmaz KS, Elbi C, Korkmaz CG, Loda M, Hager GL, Saatcioglu F. Molecular cloning and characterization of STAMP1, a highly prostate-specific six transmembrane protein that is overexpressed in prostate cancer. J Biol Chem 2002; 277:36689-96.

[13] Schroeder JT, Lichtenstein LM, MacDonald SM. An immunoglobulin E-dependent recombinant histamine releasing factor induces IL-4 secretion from human basophils. J Exp Med 1996; 183:1265-70.

[14] Schroeder JT, Lichtenstein LM, MacDonald SM. Recombinant histamine-releasing factor enhances IgE dependent IL-4 and IL-13 secretion by human basophils. J Immunol 1997; 159:447-52.

[15] Bheekha-Escura R, Chance SR, Langdon JM, MacGlashan DW Jr, MacDonald SM. Pharmacologic regulation of histamine release by the human recombinant histamine-releasing factor. J Allergy Clin Immunol 1999; 103:937-43.

[16] Wantke F, MacGlashan DW Jr, Langdon JM, MacDonald SM. The human recombinant histamine releasing factor: Functional evidence that it does not bind to the IgE molecule. J Allergy Clin Immunol 1999; 103:642-8.

[17] Bheekha-Escura R, MacGlashan DW Jr, Langdon JM, MacDonald SM. Human recombinant histamine-releasing factor activates human eosinophils and the eosinophilic cell line, AML14-3D10. Blood 2000; 96:2191-8.

[18] Kashiwakura J, Ando T, Matsumoto K, et al. Proinflammatory role of histamine-releasing factor in mouse models of asthma and allergy. J Clin Invest 2012; 122:218-28.

[19] Vonakis BM, Sora R, Langdon JM, Casolaro V, MacDonald SM. Inhibition of cytokine gene transcription by the human recombinant histamine-releasing factor in human $\mathrm{T}$ lymphocytes. J Immunol 2003; 17:3742-50.

[20] Kang HS, Lee MJ, Song H, et al. Molecular identification of IgEdependent histamine-releasing factor as a B cell growth factor. J Immunol 2001; 166:6545-54.

[21] Yoneda K, Rokuta, K, Nakamura Y, Yanagawa H, Kondo-Teshima S, Sone S. Stimulation of human bronchial epithelial cells by IgEdependent histamine-releasing factor. Am J Physiol Lung Cell Mol Physiol 2004; 286:L174-81.

[22] Xu A, Bellamy AR, Taylor JA. Expression of translationally controlled tumour protein is regulated by calcium at both the transcriptional and post-transcriptional level. Biochem J 1999; 3:683-9.

[23] Gachet Y, Tournier S, Lee M, Lazaris-Karatzas A, Poulton T, Bommer UA. The growth-related, translationally controlled protein P23 has properties of a tubulin binding protein and associates transiently with microtubules during the cell cycle. J Cell Sci 1999; 112:1257-71

[24] Rid R, Onder K, Trost A, et al. H2O2-dependent translocation of TCTP into the nucleus enables its interaction with VDR in human keratinocytes: TCTP as a further module in calcitriol signalling. $\mathbf{J}$ Steroid Biochem Mol Biol 2010; 118:29-40.

[25] Fenner BJ, Scannell M, Prehn JH. Expanding the substantial interactome of NEMO using protein microarrays. PLoS One 2010; 5:e8799. 
[26] Zhang D, Li F, Weidner D, Mnjoyan ZH, Fujise K. Physical and functional interaction between myeloid cell leukemia 1 protein (MCL1) and Fortilin. The potential role of MCL1 as a fortilin chaperone. J Biol Chem 2002; 277:37430-8.

[27] Yang Y, Yang F, Xiong Z, et al. An N-terminal region of translationally controlled tumor protein is required for its antiapoptotic activity. Oncogene 2005; 24:4778-88.

[28] Arcuri F, Papa S, Carducci A, et al. Translationally controlled tumor protein (TCTP) in the human prostate and prostate cancer cells: expression, distribution, and calcium binding activity. Prostate $2004 ; 60: 130-40$.

[29] Vercoutter-Edouart AS, Czeszak X, Crépin M, et al. Proteomic detection of changes in protein synthesis induced by fibroblast growth factor-2 in MCF-7 human breast cancer cells. Exp Cell Res 2001; 262:59-68.

[30] Chung S, Kim M, Choi W, Chung J, Lee K. Expression of translationally controlled tumor protein mRNA in human colon cancer. Cancer Lett 2000; 156:185-90.

[31] Tuynder M, Fiucci G, Prieur S, et al. A. Translationally controlled tumor protein is a target of tumor reversion. Proc Natl Acad Sci USA 2004; 101:15364-9.

[32] Li F, Zhang D, Fujise K. Characterization of fortilin, a novel antiapoptotic protein. J Biol Chem 2001; 276: 47542-9.

[33] Susini L, Besse S, Duflaut D, et al. A. TCTP protects from apoptotic cell death by antagonizing bax function. Cell Death Differ 2008; 15:1211-20.

[34] Rho SB, Lee JH, Park MS, et al. Anti-apoptotic protein TCTP controls the stability of the tumor suppressor p53. FEBS Lett 2011; 585:29-35.

[35] Amson R, Pece S, Lespagnol A, et al. Reciprocal repression between P53 and TCTP. Nat Med 2011; 18(1): 91-9.

[36] MacDonald SM, Kagey-Sobotka A, Proud D, Naclerio RM, Lichtenstein LM. Histamine-releasing factor: release mechanism and responding population J Allergy Clin Immunol 1987; 79:248 (Abstract)

[37] MacDonald SM. Histamine releasing factors and IgE heterogeneity. In: Middleton E, Reed CE, Ellis EF, Adkinson NF, Yunginger JW, Busse WW, Eds. Allergy: Principles and Practice. $4^{\text {th }}$ ed. St. Louis: CY Mosby 1993; pp.1-11.

[38] Alam R, Rozniecki J, Salmaj K. A mononuclear cell derived histamine releasing factor (HRF) in asthmatic patients. Histamine release from basophils in vitro. Ann Allergy 1984; 53:66-9.

[39] Alam R, Rozniecki J. A mononuclear cell-derived histamine releasing factor in asthmatic patients.II. Activity in vivo. Allergy 1985; 40:124-9.

[40] Alam, R, Kuna P, Rozniecki J, Kuzminska, B. The magnitude of the spontaneous production of histamine-releasing factor (HRF) by lymphocytes in vitro correlates with the state of bronchial hyperreactivity in patients with asthma. J Allergy Clin Immunol 1987; 79:103-8.

[41] Sampson HA, Broadbent KR, Bernhisel-Broadbent J. Spontaneous release of histamine from basophils and histamine-releasing factor in patients with atopic dermatitis and food hypersensitivity. N Engl J Med 1989; 321:228-32.

[42] Kuna P, Alam R. Kuzminska B, Rozniecki J. The effect of preseasonal immunotherapy on the production of histamine-releasing factor (HRF) by mononuclear cells from patients with seasonal asthma: results of a double-blind, placebo-controlled, randomized study. J Allergy Clin Immunol 1989; 83:816-82.

[43] Brunet C, Bédard PM, Lavoie A Jobin M, Hébert J. Allergic rhinitis to ragweed pollen. II. Modulation of histamine-releasing factor production by specific immunotherapy. J Allergy Clin Immunol 1992; 89:87-94.

[44] MacDonald SM. Histamine-releasing factors. Curr Opin Immunol 1996; 8:778-83.

[45] Langdon J, Anders K, Lichtenstein LM, MacDonald SM. Atopics translate mRNA for the IgE-dependent histamine releasing factor (HRF) more effectively than normal. J Allergy Clin Immunol 1995; 95:336 (Abstract).

[46] Schroeder JT. Basophils: Beyond effector cells of allergic inflammation. Adv Immunol 2009; 101:123-61.

[47] MacDonald SM, White JM, Kagey-Sobotka A, MacGlashan DW $\mathrm{Jr}$, Lichtenstein LM. The heterogeneity of human IgE exemplified by the passive transfer of $\mathrm{D}_{2} \mathrm{O}$ sensitivity. Clin Exp Allergy 1991; 21:133-8.
[48] MacDonald SM, Schleimer RP, Kagey-Sobotka A, Gillis S, Lichtenstein LM. Recombinant IL-3 induces histamine release from human basophils. J Immunol 1989; 142:3527-32.

[49] Chen SH, Wu PS, Chou CH, et al. A knockout mouse approach reveals that TCTP functions as an essential factor for cell proliferation and survival in a tissue- or cell type-specific manner. Mol Biol Cell 2007; 18:2525-33.

[50] Yueh-Chiao Y, Xie L, Langdon JM, et al. The effects of overexpression of Histamine Releasing Factor (HRF) in a transgenic mouse model. PLoS One 2010; 5:1-12.

[51] Seder RA, Paul WE, Dvorak AM, et al. Mouse splenic and bone marrow cell populations that express high-affinity Fc epsilon receptors and produce interleukin 4 are highly enriched in basophils. Proc Natl Acad Sci USA 1991; 88:2835-9.

[52] Min B, Paul W. Basophils and type 2 immunity. Curr Opin Hematol 2008; 15:59-63.

[53] Obata K, Mukai K, Tsujimuxa Y, et al. Basophils are essential initiators of a novel type of chronic allergic inflammation. Blood 2007; 110:913-20.

[54] Jacobsen EA, Ochkur SI, Pero RS, et al. Allergic pulmonary inflammation in mice is dependent on eosinophil-induced recruitment of effector T cells. J Exp Med 2008; 205:699-710.

[55] Lee JJ, Dimina D, Macias MP, et al. Defining a link with asthma in mice congenitally deficient in eosinophils. Science 2004; 305:1773-6.

[56] Mayr SI, Zuberi RI, Zhang M, et al. IgE-dependent mast cell activation potentiates airway responses in murine asthma models. J Immunol 2002; 169:2061-8.

[57] Vonakis BM, MacGlashan Jr DW, Vilariño N, Langdon JM, Scott RS, MacDonald SM. Distinct characteristics of signal transduction events by Histamine Releasing Factor/Translationally Controlled Tumor Protein (HRF/TCTP)-induced priming and activation of human basophils. Blood 2008; 111:1789-96.

[58] Dombrowicz D, Flamand V, Brigman KK, Koller BH, Kinet JP. Abolition of anaphylaxis by targeted disruption of the high affinity immunoglobulin E receptor alpha chain gene. Cell 1993; 75:96976.

[59] Oettgen HC, Martin TR, Wynshaw-Boris A, Deng C, Drazen JM, Leder P. Active anaphylaxis in IgE-deficient mice. Nature 1994; 370:367-70.

[60] Miura K, Schroeder JT, Hubbard WC, MacGlashan DW Jr. Extracellular signal-regulated kinases regulate leukotriene $\mathrm{C} 4$ generation, but not histamine release or IL-4 production from human basophils. J Immunol 1999; 162:4198-206.

[61] Kepley CL, Youssef L, Andrews RP, Wilson, BS, Oliver JM. Syk deficiency in nonreleaser basophils. J Allergy Clin Immunol 1999; 104:279-84.

[62] Lavens-Phillips SE, MacGlashan DW Jr. The tyrosine kinases p563/56lyn and p72syk are differentially expressed at the protein level but not at the messenger RNA level in nonreleasing human basophils. Am J Respir Cell Mol Biol 2000; 23:566-71.

[63] Vilariño N, Miura K, MacGlashan DW Jr. Acute IL-3 priming upregulates the stimulus-induced Raf-1-Mek-Erk cascade independently of IL-3-induced activation of Erk. J Immunol 2005; 175:3006-14.

[64] Vonakis BM, Gibbons S Jr, Sora R, Langdon JM, MacDonald SM. Src homology 2 domain-containing inositol 5' phosphatase is negatively associated with histamine release to human recombinant histamine releasing factor in human basophils. J Allergy Clin Immunol 2001; 108:822-31.

[65] Vonakis BM, Vasagar K, Gibbons SP Jr, et al. Basophil FcepsilonRI histamine release parallels expression of Src-homology 2containing inositol phosphatases in chronic idiopathic urticaria. J Allergy Clin Immunol 2007; 119:441-8.

[66] Krystal G. Lipid phosphatases in the immune system. Immunology 2000; 12:397-403.

[67] Huber M, Helgason CD, Damen JE, Liu L, Humphries RK, Krystal G. The src homology 2 containing inositol phosphatase (SHIP) is the gatekeeper of mast cell degranulation. Proc Natl Acad Sci USA 1998; 95:11330-5.

[68] Rohrschneider LR, Fuller JF, Wolf I, Liu Y, Lucas DM. Structure, function and biology of SHIP proteins. Genes Dev 2000; 14:50520 .

[69] Scharenberg AM, Kinet J-P. PtdIns-3,4,5-P3: a regulatory nexus between tyrosine kinases and sustained calcium signals. Cell 1998; 94:5-8. 
[70] Lioubin MN, Algate PA, Tsai S, Carlberg K, Aebersold A, Rohrschneider LR. p150Ship, a signal transduction molecule with inositol polyphosphate-5-phosphatase activity. Genes Dev 1996; 10:1084-95.

[71] Brauweiler AM, Tamir I, Cambier JC. Bilevel control of B-cell activation by the inositol 5-phosphatase SHIP. Immunol Rev 2000; 176:69-74.

[72] Miura K, Lavens-Phillips S, MacGlashan Jr DW. Localizing a control region in the pathway to $\mathrm{LTC}_{4}$ secretion following stimulation of human basophils with anti-IgE antibody. J Immunol 2001; 167:7027-37.
[73] Vilarino N, MacGlashan Jr D. Transient transfection of human peripheral blood basophils. J Immunol Methods 2005; 296:11-8.

[74] Didichenko SA, Spiegl N, Brunner T, Dahinden CA. IL-3 induces a Pim1-dependent antiapototic pathway in primary human basophils. Blood 2008; 112:3949-58.

[75] Langdon JM, Schroeder JT, Vonakis BM, Bieneman AP, Chichester K, MacDonald SM. Histamine-releasing factor/translationally controlled tumor protein (HRF/TCTP)-induced histamine release is enhanced with SHIP-1 knockdown in cultured human mast cell and basophil models. J Leukoc Biol 2008; 84:1151-8.

Received: January 25, 2012

() Susan M. MacDonald; Licensee Bentham Open.

This is an open access article licensed under the terms of the Creative Commons Attribution Non-Commercial License (http://creativecommons.org/licenses/by-nc/3.0/) which permits unrestricted, non-commercial use, distribution and reproduction in any medium, provided the work is properly cited. 